Proceedings of the 24th International Symposium "The Environment and the Industry" (E-SIMI 2021), 24 September 2021, online event

\title{
Betula pendula Ssp. distribution and growth in the sub-Carpathian curvature
}

\author{
MIHAI HAPA*, LUCIAN DINCA \\ "Marin Dracea" National Institute for Research and Development in Forestry, 128 Eroilor, Voluntari 077190, \\ icas@icas.ro, Bucuresti, Romania. \\ *Corresponding author: ionutmihaihapa@gmail.com
}

$\begin{array}{lll}\text { Received: } & \text { Accepted: } & \text { Published: } \\ 29.07 .2021 & 11.11 .2021 & 17.12 .2021\end{array}$

\begin{abstract}
Birch ssp. in the sub-Carpathians curvature can be found in composition with beech and other resinous species, unevenly distributed from the mountain peaks at around $1200 \mathrm{~m}$ down to 500-600, mainly from high hills to depressions at $600 \mathrm{~m}$, rarely seen on plain sites, crossing different geomorphological structures and overall accounting for 3857.1 ha. The main objectives of the paper was to analyze the site and stand characteristics of Betula pendula ssp. Roth. in the subCarpathians curvature as followed: stand structure, stand types and stand site types, soils and different metrics, from growth to yields and its connectivity.

The ecological adaptability to climate and soil and early fast growth, makes silver birch fulfill the overall requirements as a pioneer species, mostly naturally regenerated. Birch distribution is highly influenced by stand structure having low proportion in compositions, mean height of $15 \mathrm{~m}$ at age 50 and a diameter of 20m. Regarding site characteristics is more common found on fertile soils, corrugated or fragmented site type with a slope of $20-50^{\circ}$ and it is distributed as secondary species in stands, averaging $750 \mathrm{~m}$ in attitude, ranging from 500 to $1200 \mathrm{~m}$, $90 \%$ being in mixtures with other species with a mean annual increment of approximately $7 \mathrm{~m}^{3} / y e a r / h a$ regardless of stand site type. As an early successional species, it serves as a first colonizer but secondary species and quite often as an ecological instrument to improve the soil characteristics, biodiversity and prevent landslides in certain sites, lacking economic value other than fuel wood or other non-wood products.
\end{abstract}

Keywords: birch, stand, structure, characteristics, distribution

\section{INTRODUCTION}

Betula pendula Roth.'Silver birch' natural distribution varies from large areas in Europe and Asia to the shores of Atlantic Ocean up to Western and Central Siberia. It can be found in Romania on hilly and mountainous regions, in oak groves and evergreen stands distributed from low altitudes at 250 $\mathrm{m}$ at Hanul Conachi up to $1550 \mathrm{~m}$ on sunny slopes [1, 2].

The main objectives of this paper is to analyze the characteristics of Betula pendula Roth. in Curvature Sub-carphatians, such as age, canopy cover, mean height, soil type and respectively, forest sites and types and their linkages.

Considered a pioneer light-demanding species, it has low requirements regarding climate and soil, thriving during early stages of secondary vegetation succesion. Grows rapidly on poor soils from rocky sites to peat lands and has the optimum growth on fairly-fertile, well-drained limestone sites $[2,3]$. Ecotypes in Romania are limited, from dry sites to peat lands and bogs. 
Even though it has a rather shallow crown, birch is considered to mitigate the erosional process, mainly on rocky sites improving the soil conditions for species in the mixture [3]. In Nordic countries, forest managers used to eliminate it from the forests on the premises that 'a birch somewhere is a missed spot for spurce' yet, pulp industries nowadays consumes more than $80 \%$ of all commercial birch wood (excluding firewood) [4]. In some cases, curly birch (Betula pendula var. Carrelica) receives high economical value due to its veneers and ornamental wood products that the curly grains produces [5]. Moreover, tree parts have been used in traditional medicine treating diseases such as urinary tract disorders, severe infections or inflammations [6].

The forests situated in the Curvature sub-Carpathians fulfills multiple ecosystem services such as: biodiversity [7], non-forest wood products [8,9], medicinal plants [10], game optimisation through appropriate management $[11,12]$, forest secondary products such as fruits [13] or other [14].

\section{MATERIAL AND METHODS}

\section{Study area}

The analysis took place in SE part of Romania, in the sub-Carpathian curvature (Fig.1), which establishes the transition between mountain area and the plains through depression and valleys, ranging from $950-1200 \mathrm{~m}$ on peaks through level differences of $200-450 \mathrm{~m}$. Arranged under the form of continuous rows parallel to the mountains and structures by thin loess deposits and young sedimentary rocks such as marls, sandstones and clays, are seen as weaker than the mountainous layer, often with corrugated stories 'linked with one another in labyrinth fashion [15].

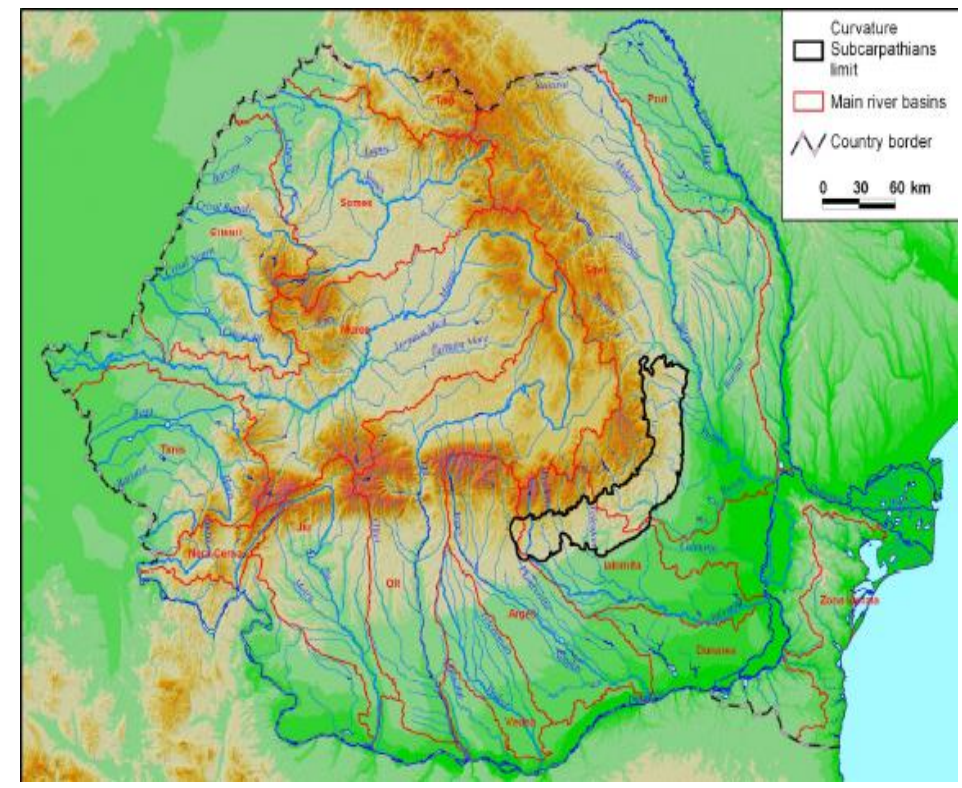

Fig. 1. Study area

The presence of foehn leads to 'warm' periods in winter with an increment of 0.5-1.5 degrees on peaks, precipitations varying to $480 \mathrm{~mm} /$ year, simulating an active morphodynamic activity [16]. The high relative slope $>58^{\circ}$ and the high drainage system makes the area predisposed to erosions with sediment discharges sometimes going over $4.000 \mathrm{~m}^{3 /} \mathrm{km}^{2} /$ year, landslides becoming a common issue [17].

\section{Method}

The data which describes birch situation in the Curvature subcarpathians was taken from the forest management plans provided by Romanian National Forest Agency ROMSILVA. It was sorted based on forest directorates and the quantative details were extracted such as the ammount of hectares which birch occupies according to different characteristics of birch stands. Moreover, site and stand related characteristics such as site structure, forest stand type, soils and site types were analyzed based on their distribution in hectares across the studied area. 
Through the use of MS Excel the data was analyzed and plotted against each other in some cases to provide a better overview and a comprehensive analysis on birch stands in the Curvature subcarpathians. The analyzed data should provide an overview regarding the use of birch in the study area and its related problematic situations.

\section{RESULTS AND DISCUSSIONS}

\section{Birch distribution in the sub-Carpathians curvature}

Betula pendula distribution across the sub-Carpathians curvature (Fig.2), according to the data analysis accounts as 3857.1 ha. The biggest share of birch forests was found in Cislau Forest District- 994.9 ha and Vintila Voda Forest District - 937.8 ha, followed at the bottom low by Dumitresti Forest District - 102.3 ha, Voinesti Forest District - 25.5 ha and Moreni Forest District with 10.7 ha of birch forests (Fig.3).

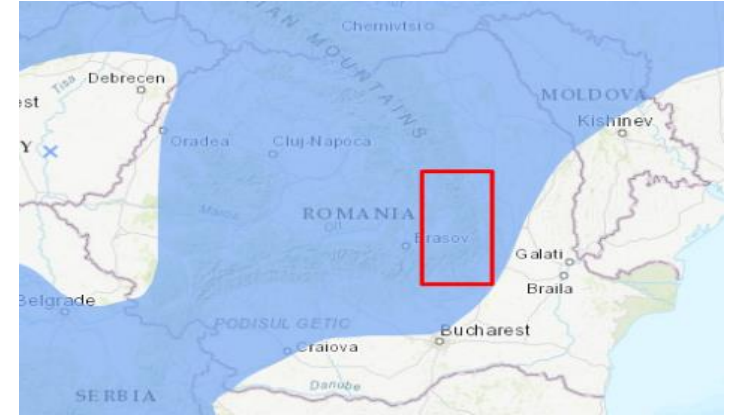

Fig. 2. Birch distribution in the area studied

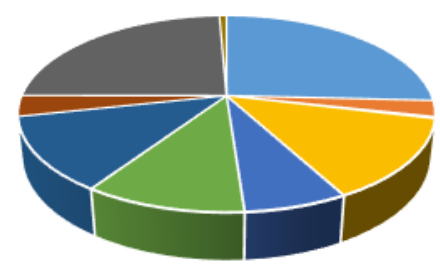

- Cislau

- Dumitresti

- Moreni

- Parscov

- Pucioasa

- Slanic

- Valeni

- Vidra

- VintilaVoda

- Voinesti

\section{Site conditions of birch stands in sub-Carpathian's curvature}

Landforms of Birch forests in the study area seems to be predominantly on relative slopes (61\%), upper slope (16\%), middle slope (15\%), low slope (7\%) and it plummets around $1 \%$ on plateaus $(1 \%)$, manure cones $(0.06 \%)$ and ravine $(0.06 \%)$ according to Fig. 4.

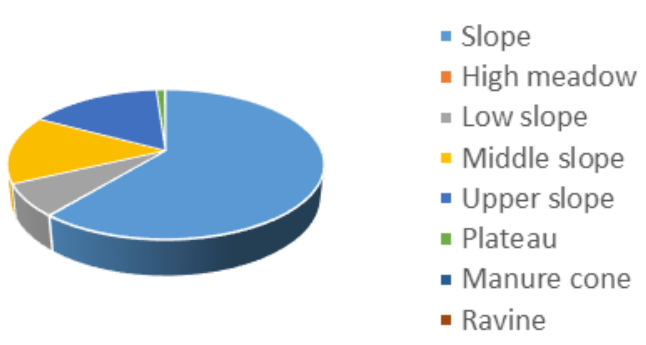

Fig. 4. Landforms distribution in hectares

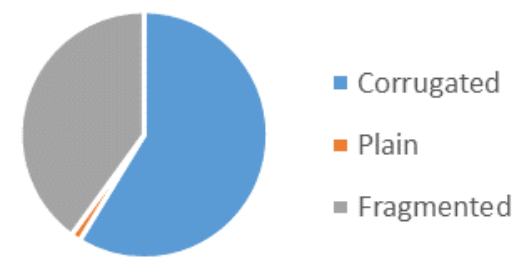

Fig. 5. Land configuration in hectares

Predominant land configuration seems to fluctuate between corrugated and fragmented areas with $59 \%$ on 1543.4 ha and respectively $40 \%$ on 2266.2 ha, plain areas reaching the lowest point at $1 \%$ with only 49 ha as presented in Fig. 5.

The average altitude varies from $507 \mathrm{~m}$ at Moreni Forest District, up to $914 \mathrm{~m}$ at Pucioasa Forest District with an overall of $750 \mathrm{~m}$. As it can be seen in Fig. 6, the chart outlines the area distribution in hectares according to the level of slope in degrees, the main area being concentrated towards a relative deep slope of $21-50^{\circ}$, averaging at $30^{\circ}$, with its peak at $70^{\circ}$ in one management unit at Cislau Forest District. The stands are mainly located in $\mathrm{N}$ and $\mathrm{S}$ exposure, with slight changes, land exposure being presented in Fig. 7. In Britain, silver birch is distributed across the South and East while downy birch gets more common in the North and West [18].

In the areas studied, birch can be found on a diverse type of soils (Fig. 8). Even if it thrives best on fertile, eutrophic high base saturation eutric cambisols (1562.6 ha), it seems to grow good on medium base saturation dystric cambisols (407.6 ha), but needing some ameliorative actions. It is found on lithosol on medium/loam sand and seen to colonize lands with imperfect drainage on 
fluvisols. It is also found on erodisols, where landslides are common and on podzols where the spodic horizon is characteristic with the accumulation of metal oxides such as iron and aluminium [19].

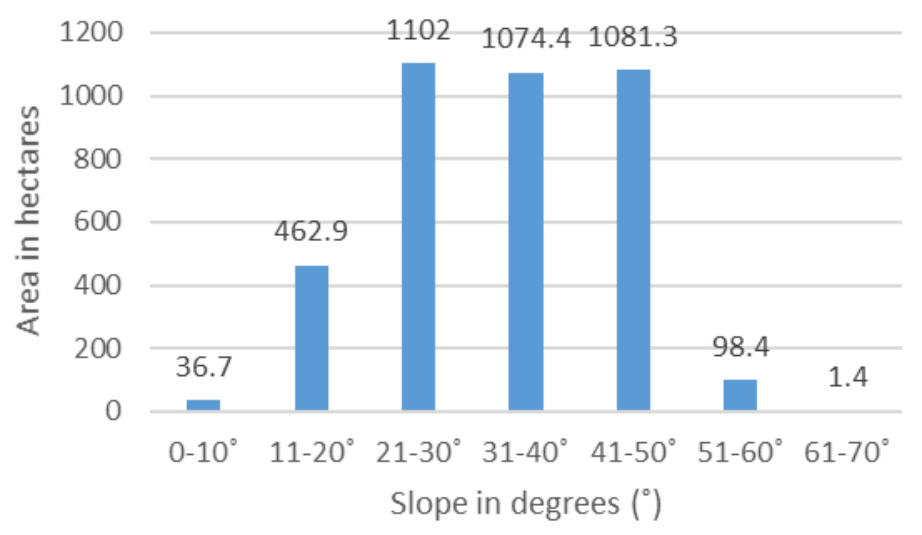

Fig. 6. Slope distribution according to hectares
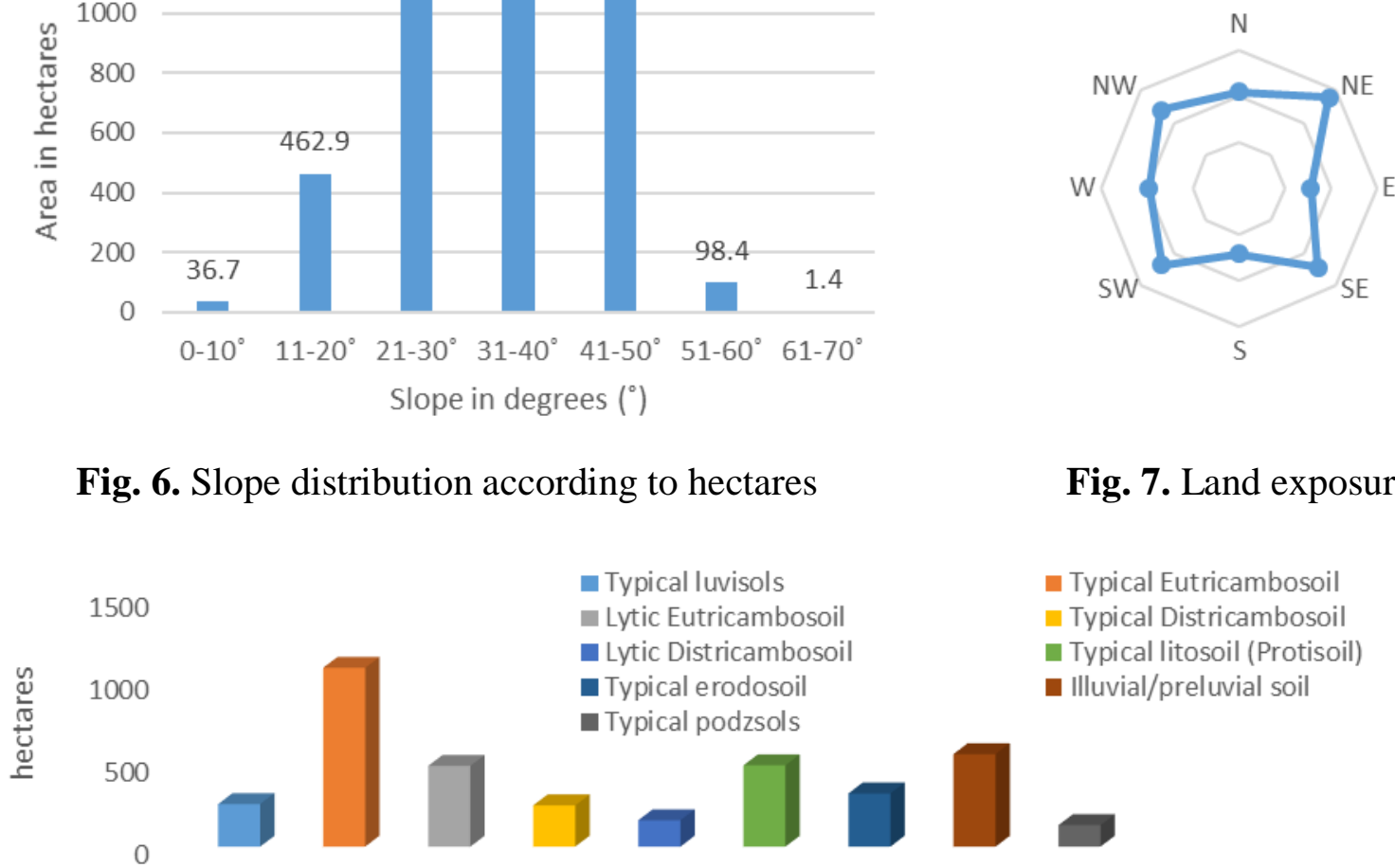

Fig. 7. Land exposure

Typical Eutricambosoil

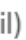

\section{Fig. 8. Soil classification}

(1)

\section{$\sqrt{3}$}

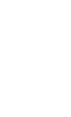

\section{Betula pendula Ruth. stand characteristics in the sub-Carpathians curvature}

Most common stand types (Fig. 9) for birch are mountain common beech stands with different type of flora on 1171.6 ha and closely followed in mixtures in hilly areas on 514 ha. Moreover, it comes in mixtures in pine stands (116.4 ha) at 700-900 $\mathrm{m}$ and usually accompanies resinous species [20] and beech on sites with average productivity.
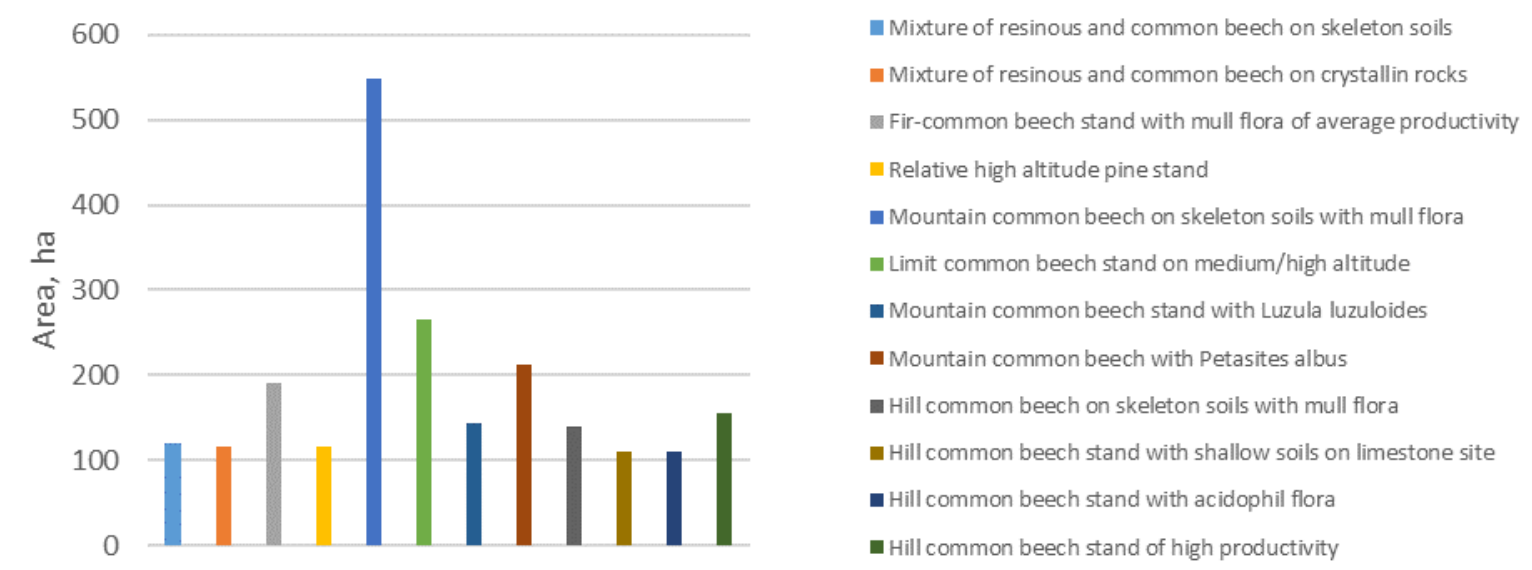

Fig. 9. Stand types

Regarding the stand distribution according to age in Fig. 10, approximately $80 \%$ of volume is concentrated around the 20-75 stand age interval with a total of $3100 \mathrm{mc}$ and an average current growth of $0.5 \mathrm{mc} / \mathrm{year}$ at the average age of 47 . 


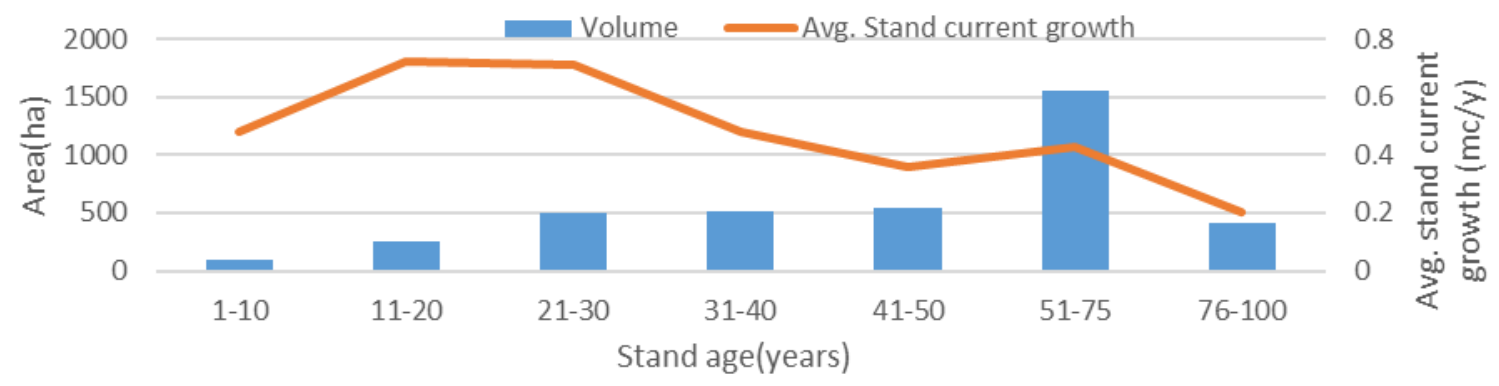

Fig. 10. Stand age and avg. current growth

Predominantly naturally regenerated, birch in the Curvature Sub-Carpathians is found in mixtures (1827 ha) and unevenly distributed (1880 ha) compositions.

Regarding forest stand site, birch experiences high distribution (>1000 ha) in mountain mixtures, Bm average edaphic eutricambisoil with Asperula-Dentaria (3332) and in Mountain- pre-mountain Bi common beech stand, rock land and excessive erosion (4120). Best growth is recorded in Mountain - pre-mountain, Bm average edaphic eutric cambisol common beech stands with Asperula dentaria (4420) with $13.7 \mathrm{~m}^{3} / \mathrm{ha}$ at the age of 49 . Protection forests accounts as $80 \%$ (3007.3 ha) under functional group 1, the rest going to functional group 2, forests with multiple functions. Moreover, since its high proportion in mixt stands, approx. 1600 ha has the purpose of a regular forests with common assortments, mainly wood for timber, constructions and pulp and paper industry whereas more than $50 \%$ satisfies the ecologic purpose as a forest submitted to exceptional conservation regimes.

The stand quality varies from medium (13811 mc on $1310 \mathrm{ha}$ ), fluctuating between low and very low quality ( $8491 \mathrm{mc}$ on $2220 \mathrm{ha}$ ) while $10 \%(3058 \mathrm{mc}$ ) of the total volume goes to high and really high quality on 335.4 ha. Tough as species, birches value exceeds the expectations and improves soil and nurses to protect the other species from mainly frost damage, rarely growing to large dimensions [18].

\section{Site and stand requirements}

Silver birch distribution occupies mostly the upper and middle slope, frequently colonizing the fragmented and corrugated land at relatively high altitude, approximately 800-900 m predominately on quite deep slopes ranging from 20-50 degrees. Due to its fertility, adequate moisture and aeration, eutric cambisols are the most colonized, found on more than 50\% of the area [21-23]. It is less found on clay and silt soils due to its compactness, preferring sandy and fine sandy soils overall. Birch on infertile soils can hardly be seen, mainly mitigating landslides or imperfect drainage.

Mainly naturally regenerated, birch becomes a secondary species and usually in low proportion in stands, filling the gaps and found unevenly distributed, often in mixtures. Even though the age varies from 1-100 years, the area occupied by birch is concentrated around the usual vigorous age distribution of 20-75, when the birch fully fulfils its ecological functions and acting as a support species.

Regardless its characteristics as a pioneer species, birch seems to prefer mountainous and highaltitude areas, mixtures with beech, rarely with softwood species. Predominantly distributed on stand type of mountain common beech on fertile soils at high altitude, sometimes it can be found in composition with resinous species, especially in high altitude pine stands to a certain extend. In the boreal zone of Northern Europe, they are co-dominant or even dominant species in late-successional vegetation, mainly seen at high elevation limit, strongly connected with Betula pubescens consolidating the alpine tree-line stands in Nordic countries. Fitting the climate change, both silver and downy birch can help mitigate the global changes through its integration in diverse productive mixed tree stands as it is in this case, with beech, fir and spruce at high altitude. 


\section{Growth and yield}

Stand site classification provides a better overview towards the growth and yield of birch in the studied area. Since it is mainly found in small percentages in stand compositions, on fertile mountain-pre-mountain stand site type with common beech on average edaphic eutric cambisol. It can generate approximately $100 \mathrm{~m}^{3} /$ ha at the age of 45-50. Nevertheless, the highest distribution of birch is found on average to high fertile stand site type yet with a mixture of hard and soft woods, where it records slightly more than $130 \mathrm{~m}^{3} /$ ha at the age of $50[24,25]$. On best stand site types, it reaches up to $20 \mathrm{~m}$ in height at the age of 60 yet their vitality becomes weak and very weak overall, distributed across the altitude of 900-1100m.

On the other hand, regardless of stand site type classifications, an amount of $7 \mathrm{~m}^{3} /$ year/ha is accounted for birch at approximate medium height of $15 \mathrm{~m}$ across all area thus the Eichorn's rule becomes relevant [26]. Regarding birch monocultures or stands where it is considered a dominant species it is recorded a $9 \mathrm{~m}^{3} / \mathrm{ha} /$ year at the age of 54 whereas in mixed stands where birch proportion is below $50 \%$, it is recorded a $6.6 \mathrm{~m}^{3} /$ year/ha at the age of 50 , medium height being quite similar in all cases, $14-15 \mathrm{~m}$.

Since it's managed for common assortments and integrally nature protection, the quality of birch stands is at the bottom on most of the area, proving the point that it's more of a complementary species rather than in the dominant story, $80 \%$ of the volume and area going into protection forests, respectively exercising the ecological ecosystem functions.

\section{CONCLUSIONS}

The analysis has showed the multiple roles of birch in a diverse stand, fulfilling most ecosystem services with respect to the climate change and different changes in forest structure. Based on the data analysed, it thrives on a wide range of soils, from high productivity stand soil type to less fertile and quite poor with high predisposition to landslide such as rendzine. Having a short lifespan and low durability, it is not cultivated for veneer or other high-quality assortments, being mainly used to improve forest resilience and biodiversity.

Since its tremendous ability to regenerate naturally through its wide seed dispersal, it can restore the production function of the forest improving at the same time the soil fertility through its roots and shallow crown, increasing species richness in the understory and below ground. However, its fast growth and early successional characteristics increases the competition in early stage, having a negative impact if not managed accordingly.

It is recommended that Betula pendula ssp. take part in mixed stands more often, the species being known to mitigate desertification and soil depletion. Being very suitable in mixed stands, its future use in the stand provides cover for seedlings of more valuable species improving the soil biodiversity and a better nutrient fixture below ground.

Thus, future research is needed and should be aimed on the impact of birch in mixtures regarding its characteristics as support for valuable species growth and the ecological role in land restoration.

\section{ACKNOWLEDGMENTS}

The authors thank to the State Forest Administration RNP ROMSILVA for providing the required data in order to carry on with the research. Moreover, many thanks to our colleagues from the institute for certain feedbacks and providing different point of views.

\section{REFERENCES}

[1] Yurkovskaya, T., Bucov. For., 20, no. 2, 2020, p. 139.

[2] Beck, P., Caudull,o G., de Rigo, D., Tinner, W., European Atlas of Forest Tree Species, Publication Office of the European Union, Luxembourg, 2016, p. 70

[3] Sofletea, N., Curtu, L., Dendrologie, Editura Universitatii Transilvania, Brasov, 2007, p. 191198.

[4] Dubois, H., Verkasalo, E., Claessens, H., Forests, 11, no. 3, 2020, p. 336. 
[5] Hynynen, J., Niemisto, P., Vihera-Aarnio, A., Brunner, A., Hein, S., Velling, P., Forestry, 83, no. 1, 2010, p. 103.

[6] Demirci, B., Demirci, F., Can Baser, K.H., Franz, G., Evid. Based Complementary Altern. Med., 1, no. 3, 2004, p. 301.

[7] Dinca, L., Bratu, I., Bulletin UASVM Agriculture, 77, no. 2, 2020, p. 9.

[8] Vechiu, E., Dinca, M., Dinca, L., Ann. West Univ. Timis., Ser. Biol., 22, no. 1, 2019, p. 57.

[9] Tiwary, A., Vilhar, U., Zhiyanski, M. , Stojanovski, V., Dinca, L., Urban Ecosys., 23, no. 3, 2010, p. 645.

[10] Vasile, D., Enescu, M., Dinca, L., Sci. Papers Ser. Managem., Econ. Eng. Agric. Rural Dev., 18, no. 1, 2018, p. 523.

[11] Ciontu, C., Dinca, L., Enescu, C., Onet, A., Onet C., Nat. Res. Sustenable Dev., 8, no. 2, 2018, p. 138.

[12] Crisan, V., Marcu, C., Dinca, L., Annals Univ. Craiova: Agriculture, Montanology, Cadastre Series, 50, no. 2, 2020, p. 87.

[13] Tudor, C., Constandache, C., Dinca, L., Proceedings of X International Agriculture Symposium, Agrosym 2019, Jahorina, Bosnia and Herzegovina, 3-6 October 2019, p. 1920.

[14] Braga, C., Dinca, L., Curr. Trends Nat. Sci., 8, no. 15, 2019, p. 73.

[15] Muica, N., Nancu, D., Turnock. D., GeoJournal, 50, no. 2, 2000, p. 199.

[16] Mac, I., Rev. Roum. Geogr, 36, 1992, p. 81.

[17] Micu, M., Balteanu, D., Landslides, 10, no. 3, 2013, p. 323.

[18] Savill, P. S., The Silviculture of Trees used in British Forestry, CABI, Oxford, 2019, p. 41-47.

[19] Dinca, L., Achim, F., Sci. Papers Ser. Managem., Econ. Eng. Agric. Rural Dev., 19, no. 3, 2019, p. 183.

[20] Dinca, L., Murariu, G., Iticescu, C., Budeanu, M., Murariu, A., Int. J. Conserv. Sci. , 10, no. 4, 2019, p. 781.

[21] Crisan, V., Dinca, L., Onet, A., Onet, C., Nat. Res. Sustenable Dev., 9, 2017, p. 21.

[22] Onet, A., Dinca, L., Teusdea, A., Crisan, V., Braga, C., Raluca, E., Onet, C., Environ. Eng. Manag. J, 18, no. 12, 2019, p. 2643.

[23] Enescu, C.M., Dinca, L., Curr. Trends Nat. Sci., 8, no. 15, 2019, p. 114.

[24] Blaga, T., Dinca, L., Plesca, I.M., Sci. Papers Ser. Managem., Econ. Eng. Agric. Rural Dev., 19, no. 4, 2019, p. 29.

[25] Dinca, L., Vechiu, E., Onet, A., Nat. Res. Sustenable Dev., 10, no. 1, 2020, p. 91.

[26] Skovsgaard, J.P., Vanclay, J.K., Forestry, 86, no. 3, 2013, p. 305.

Citation: Hapa, M., Dinca, L., Betula pendula Ssp. distribution and growth in the sub-Carpathian curvature, Rom. J. Ecol. Environ. Chem., 2021, 3, no.2, pp. 16-22.

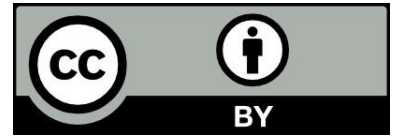

(C) 2021 by the authors. This article is an open access article distributed under the terms and conditions of the Creative Commons Attribution (CC BY) license (http://creativecommons.Org/licenses/by/4.0/). 